\title{
Meeting the copyright challenge
}

\author{
Things you can do to protect your institution
}

\author{
by Kathleen L. Amen, Judy Garrison, and Trish Keogh
}

I magine your library in the path of an oncoming storm . . . and you have no disaster preparedness plans in place. Many academic libraries may soon find themselves in similar straits. Although this cataclysm won't appear on satellite photos, it's already making headlines with alarming frequency. What's it all about? Copyright.

Those amusing student requests for $\mathrm{CD}$ burners on the library LAN should be telling us something. Implications of copyright-related activities extend beyond the library to the entire institution: faculty-produced anthologies (course-packs) are reproduced at the campus duplicating center, sold in the campus bookstore, and placed on reserve in the campus library; students use campus networks (and, often, campus-supplied devices) to access the Internet, download files, and burn their own CDs. The copyright violator of old, that occasional nuisance patron monopolizing the copier for hours, has become every student with a fondness for music and the time and desire to download files.

This new wave of copyright violations is more traceable, is more susceptible to court action, and is more apt to lead to closer scrutiny of your library's overall adherence to copyright standards. ${ }^{1}$ And the resulting legal action could be every bit as costly and ruinous as a flood or fire

What if you could develop a contingency plan for this man-made disaster? Wouldn't you try to insure against loss if you could? An institutional copyright policy, involving all segments of the college or university and supported by a campus-wide educational program and legal support, may be just the ticket. In addition to disaster preparedness plans, libraries and their parent institutions should consider adopting campus-wide policies and programs to address copyright concerns.

The Copyright Act of 1976 addressed the then newly prevalent technology of photocopiers. In response, academic libraries promptly implemented copyright policies relating to interlibrary loan procedures and in-house photocopying. However, many colleges and universities today have yet to address, on a campus-wide basis, the copyright issues brought up by the newest technological innovations. The substantial changes intellectual property law has undergone in the past few years have left librarians (and others) confused about how to apply laws originally intended solely for print media to new digital products and distribution systems.

\section{About the authors}

Kathleen L. Amen is government information librarian and Trish Keogh is cataloging librarian in the Blume Library of St. Mary's University, e-mail: acadamen@st marytx eduand pkeogh@stmarytx. edu; Judy Garrison is head of Electronic Acquisitions $\&$ Serials Control at the University of Texas at San Antonio, e-mail:jgarrison@utsa.edu 
In the spring of 2000 at St. Mary's University in San Antonio, a committee of librarians (including the authors) and professors met to study the issues and draft a copyright policy. As the scope of the problem became evident, the committee realized that a quick fix was neither possible nor desirable. The committee also agreed that the entire university community needed to be involved in the copyright policy's development, and that comprehensive and ongoing training was needed throughout the campus. This article presents some of our findings as well as our conclusions and recommendations on where to look for additional information.

Note that the volatile nature of this area, the resuit of rapidly evolving technological capabilities and legislatively mandated periodic reviews, renders all suggestions provisional. Constant monitoring of the intellectual property scene has become essential for libraries and their parent institutions. We offer a framework to modify in response to developments in the courts and in Congress. Bear in mind that fair use, which seeks a balance between the interests of copyright holders and content users, is the general principle underlying all copyright concerns in educational settings.

\section{Distance education and electronic reserves}

In response to a request from Congress, the Copyright Office delivered a report that included recommendations to promote the use of digital technology in distance education. ${ }^{2}$ Some of these are:

- update the language of the Copyright Act to reflect new technologies,

- eliminate the physical (face-to-face) classroom requirement of Section $110(2)$ of the Copyright Act of 1976, 3

- clarify the fair use doctrine, confirm its technology-neutral nature, and explain how the fair use guidelines function, and

- give the market room to develop, and reassess the issue relatively soon.

As Congress has not revisited these issues, vigilant monitoring of ongoing developments regarding distance education is especially important.

Librarians have generally approached electronic reserves - a collection of materials made available to students in digital form on a com-

\section{... the entire university}

community needed to be involved

in the copyright policy's

development, and that

comprehensive and ongoing

training was needed throughout

the campus.

puter network-as analogous to collections in traditional, nondigital formats. In addition to applying fair use standards, libraries need to limit access to electronic reserve collections to currently enrolled students, to post copyright notices on the reserve system, and to remove materials from the system at the end of the course.

\section{Music and other media}

In considering fair use standards, one should be sensitive to the five exclusive rights to a copyrighted work enjoyed by the copyright owner - the rights of distribution, reproduction, modification, public performance, and public display. Each separate right represents an obligation for the user of a copyrighted work, and each may come into play, particularly when providing Web access to multimedia. While fair use may allow inclusion of brief audiovisual clips for educational purposes, using "portions" of this type of content is more problematic than the use of printed material.

Multimedia use may require considerations beyond obtaining permission from copyright holders for the use of text and photographs. If copyrighted music is to be included, rights must be obtained to the composition; if it is to be synchronized with still or moving images, "synchronization rights" may also be required. Even if the musical piece is in the public domain, if a particular pre-existing performance or recording is to be used, permission must be obtained from those rights holders.

Use of copyrighted film and video requires obtaining multiple clearances; the copyright holder of the screenplay, the copyright holder of the original work on which the screenplay is based, the film's copyright owner, actor reuse fees, and music permissions may all apply. If Web access to the work is contemplated, given the borderless nature of the Internet, 


\section{... if we have come to regard}

media access as a right, we must

\section{be prepared to fulfill the corollary responsibilities.}

worldwide rights should also be obtained for each use."

\section{Course-packs}

Although course-packs do not necessarily involve new technologies, they may come under renewed scrutiny as overall interest in copyright issues is highlighted. Course-packs or anthologies are collections of previously copyrighted works compiled by faculty, photocopied, and sold to their students. Despite the fact that the most famous case in this area, Basic Books, Inc. v. Kinzo's Graphics Corp., 5 applied to a for-profit operation, the findings could impact any college duplicating center preparing course-packs without permission from copyright holders. Even if the center derives no profit from their sale, the fair use exemption might not apply, since the commercial nature of the entity is but one factor considered in determining fair use.

\section{Colleges/universities as online service providers}

The Digital Millennium Copyright Act's (DMCA) definition of "online service provider" (OSP) is broad enough to include any campus network. ${ }^{6}$ Educational or nonprofit status does not provide an institution with automatic exemption from the provisions of the law, but the act does offer protection from liability for infringement under certain conditions. The DMCA protections for registered OSPs only apply to the institutions' functions as a conduit and/or provider of long-term storage capacity for others' content. The protections do not exempt institution-produced content from copyright considerations.

\section{What you can do to prepare}

It has been said that the price of liberty is eternal vigilance. Whether as a means of keeping abreast of public affairs or of circumventing totalitarian regimes, the Internet has become identified with freedom. But if we have come to regard media access as a right, we must be prepared to fulfill the corollary responsibilities.

Here are some specific suggestions for meeting the copyright challenge:

- Develop an educational program for current faculty, staff, and students. Copyright awareness should be part of the orientation process for new faculty, staff, and students.

- Develop general information resources to assist personnel in complying with copyright regulations. A simple Web page with links to information may be adequate, or tutorials and guides such as those listed below may be needed.

- Provide guidance for personnel in obtaining copyright permissions, such as sample letters and how-to guides. If size or demand warrants, a particular person or office could be designated to handle requests for assistance.

- Investigate membership in the Copyright Clearance Center or some other service that provides permissions services for a flat fee.

- Decide if your institution should register as an OSP; if so, designate (and train, if necessary) an agent.

- Be sure your institution's legal team has the expertise to advise you in this very specialized area of the law.

- Develop standardized wording for notices to be posted at all points on campus (as well as on all campus Web pages) where copyright considerations should be noted. This means not only at photocopy machines, but also near scanners, in video labs, computer labs, classrooms, and even dormitories.

New technological innovations have greatly expanded information access for libraries, their patrons, and their parent institutions. However, some of the hidden costs are now becoming apparent, particularly with regard to media delivery. Dramatic developments in intellectual property law are likely to continue, and we in the academic information field must be prepared to monitor the copyright situation and adjust our practices accordingly.

\section{Notes}

1. Although, to date, no library has been named in a copyright suit, the standard proviso of stockbrokers still applies: past performance is no guarantee of future results.

2. U.S. Copyright Office. Report on Copy right and Digital Distance Education, 1999. 11 Dec. 2000. http://www.loc.gov/copyright/ docs/de_rprt.pdf. 
3. U.S. Code, vol. 17, sec. $110(2)$.

4. Note that ALA has not endorsed any multimedia fair use guidelines at this time. Note also the distinction between fair use doctrine, a part of copyright law, and fair use guidelines. While the guidelines are inspired by, they are not part of, copyright law. This distinction is important: while courts may consider such guidelines, their ultimate judgments are based on law, not agreements.

5. Basic Books, Inc. v. Kinko's Graphics Corp., 758 F.Supp. 1522 (S.D.N.Y. 1991)

6. U.S. Statutes at Lange 112 (1998):2886.
("An innovative. . ." cont. from page 719) percentage of the entering class so that all new students can benefit from the program. We expect that the college's revision of its first-year program will easily accommodate our modified orientation goals.

Morcover we must continue to solicit faculty support. Faculty who mentioned the library advisor program early in the semester reinforced our contact with students and encouraged students to meet with us in the library, and this support should continue. Most important, we need to develop longer-term evaluation methods. We will meet with faculty to see if second- and third-year students' work reflects better-developed research skills. We also hope to design and implement evaluative tools to provide quantitative data on the program's effectiveness.

\section{Conclusion}

The library advisor program reflects our emphasis on service to students, our focus on individualized instruction, and our sense that technology must be balanced by direct and personal contact. In an undergraduate environment that emphasizes research, independent study, and the use of primary sources from the beginning of a student's career, the need for a close relationship with a librarian is often as important to the student's success as his or her relationship to a faculty advisor.

Our new library program encourages a solid relationship between librarians and entering students and makes the librarian an essential connection between technology and academic success.

\section{*ChoiceReviews.online}

\section{It's more than just a database of reviews!}

$\star$

$\star$ Internet access to all CHOICE reviews since Sept. 1988 -some 80,000 reviews at your fingertips

$\star$ E-mail alerts of new reviews, based on your profile

$\star$ Create and store groups of reviews by subject, fund code, department, etc. You can even e-mail reviews to others!

$\star$ Annual subscription includes personalized password access for up to 20 users and all corresponding print issues of the magazine.

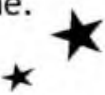

* Sign up for a free trial today! *

wWw.ChoiceReviews.org

Phone: (860)347-6933 x23 Fax: (860) 704-0465

E-mail: choiceonline@ala-choice.org

100 Riverview Center, Middletown, CT 06457 